\title{
Video Assisted Thoracoscopic Surgery (VATS) of Lymphangiomyomatosis (LAM) with Multiple Pulmonary Bullae in a Woman: A Case Report and Literature Review
}

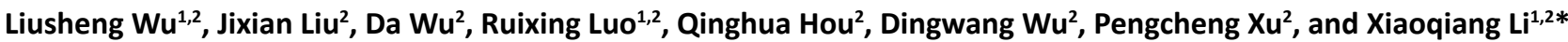 \\ ${ }^{1}$ Peking University Shenzhen Hospital, Clinical College of Anhui Medical University, Shenzhen, Guangdong, 518036, China \\ ${ }^{2}$ Department of thoracic surgery, Peking University Shenzhen Hospital, Shenzhen, Guangdong, 518036, China
}

*Corresponding author: Xiaoqiang Li, Ph.D, Professor, Peking University Shenzhen Hospital, Clinical College of Anhui Medical University, Shenzhen, Guangdong, 518036, China, E-mail: dr.lixiaoqiang@gmail.com

Received: 17 Jan, 2021 | Accepted: 01 Feb, 2021 | Published: 05 Feb, 2021

Citation: Wu L, Liu J, Wu D, Luo R, Hou Q, et al. (2021) Video Assisted Thoracoscopic Surgery (VATS) of Lymphangiomyomatosis (LAM) with Multiple Pulmonary Bullae in a Woman: A Case Report and Literature Review. J Clin Case Stu 6(1): dx.doi.org/10.16966/2471-4925.214

Copyright: (C) 2021 Wu L, et al. This is an open-access article distributed under the terms of the Creative Commons Attribution License, which permits unrestricted use, distribution, and reproduction in any medium, provided the original author and source are credited.

\section{Abstract}

Background: Pulmonary lymphangiomyomatosis is relatively rare disease and it is a systemic disease with an unknown etiology. The abnormal proliferation of smooth muscle leads to the obstruction of bronchi, lymphatic vessels and small blood vessels. At present, there are not many clinical reports on the treatment of LAM thoracoscopic surgery. So this article reports a case of LAM in a middle-aged woman and reviews of the relevant literature.

Case summary: A 46-year-old woman was admitted to the hospital with recurrent chest tightness and chest pain for 3 months. Chest X-ray Imaging examination revealed that the patient had a right liquid pneumothorax, a $75 \%$ compression of the right lung and a right subcutaneous emphysema. The right lung is filled with large patches of increased density and blurred boundaries, so the patient developed symptoms of dyspnea. The diagnosis of repeated pneumothorax was clear and there were indications for surgery. Finally, we decided to use thoracoscopy and surgical treatment to relieve the symptoms of chest tightness, chest pain and dyspnea of the patient. During the operation, extensive adhesions were seen in the right thoracic cavity, the pleura of the right lower lung layer and the lung tissue were in a relaxed state and the right lung was scattered with multiple pulmonary bullae. The endogia was used to make the right bulla from the edge of lung to resection, electrocoagulation and burning, and stop bleeding on the wound and flush the chest cavity. The pathological results reported LAM. The patient's chest tightness, discomfort and dyspnea disappeared after the operation 2 weeks. We informed the patient that there was a high risk of recurrence, but the patient refused further treatment.

Conclusion: Surgical resection under thoracoscopy is the main ways to treat LAM. This article reviews the case reports of LAM treatment in the last years, analyzes the recurrence rate of LAM resection using thoracoscopy, and discusses the clinical features and best treatment methods of LAM.

Keywords: LAM; Thoracoscopic surgery; Pulmonary bullae; Rare cases; Literature review

\section{Introduction}

LAM mostly occurs in women and the etiological mechanism is currently unclear [1]. The lungs are mostly involved, and the typical manifestation is diffuse cystic changes, which seriously affect the patient's lung function. Common respiratory symptoms of LAM include recurrent pneumothorax, chylothorax, chest tightness, chest pain, and dyspnea [2]. Repeated pneumothorax and chylothorax are the first symptoms of LAM. Because LAM tends to occur in women between 30 and 40 years old, it is speculated that it has a certain relationship with estrogen. The nuclear estrogen receptor and progesterone receptor of LAM cells are positive [3]. This theoretically can be treated for estrogen control, but there is not enough clinical trial data to support the effectiveness of actual application. In recent years, many countries and institutions have conducted large-scale random experiment to explore the treatment of LAM. Some scholars prefer conservative treatment, with rapamycin and doxycycline as the main representatives [4,5]. Other scholars prefer surgical treatment, with thoracoscopic surgical resection as the main representatives. These new treatment methods have brought LAM patients chance. Based on a case analysis and review of previous related literature, this article statistically analyzes the clinical characteristics and surgical treatment of LAM, its effectiveness, safety, and pneumothorax recurrence rate. It will provide valuable clinical treatment guidance for the future treatment of LAM.

\section{Case Presentation}

\section{Chief complaints}

A 46-year-old woman experienced chest tightness and chest pain repeatedly for 3 months, and dyspnea progressively worsened for 1 week. What is more, the patient has a history of recurrent pneumothorax. 


\section{History of past illness}

The patient had no previous medical history.

\section{Imaging examinations}

Computerized electronic scanning $(\mathrm{CT})$ scan and $3 \mathrm{D}$ reconstruction images show that there is the right liquid pneumothorax and the right lung is compressed by $75 \%$. The right lung field shows a clear area without lung texture, and the inside is compressed, the edges of the lung tissue, the ipsilateral costophrenic angle and the septum are not clear, and multiple patches of increased density of the left lower lung can be seen in the right lung and lower left lung field, with blurred edges (Figure 1).
HRCT showed that diffuse large patches and patches of increased density in the right lung, with unclear boundaries. Both lungs have multiple round-like translucent areas. The largest translucent area is located in the tongue of the left lung, with a diameter of about $15 \mathrm{~mm}$. There are cord-like and grid-like shadows under the pleura of the left lower lobe (Figure 2).

The patient also developed progressively worsening dyspnea. It is considered that there is a certain correlation with $75 \%$ of lung compression. At the same time, the lung tissue cannot be well recruited, which affects the patient's lung function and respiratory status.

Extensive membranous and cord-like adhesions in the right thoracic cavity were seen under thoracoscopy, diffuse pulmonary

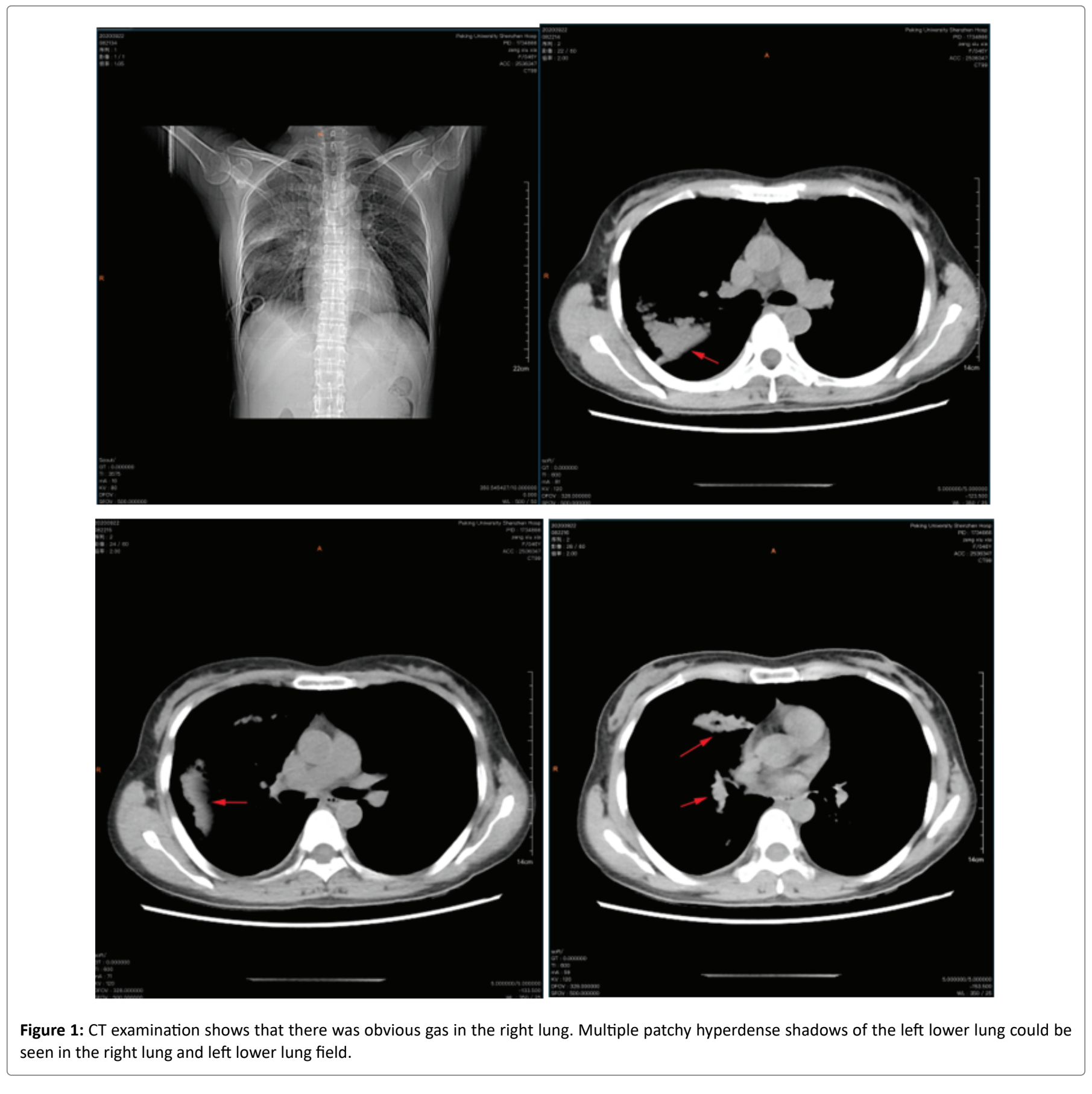

Citation: Wu L, Liu J, Wu D, Luo R, Hou Q, et al. (2021) Video Assisted Thoracoscopic Surgery (VATS) of Lymphangiomyomatosis (LAM) with Multiple Pulmonary Bullae in a Woman: A Case Report and Literature Review. J Clin Case Stu 6(1): dx.doi.org/10.16966/2471-4925.214 

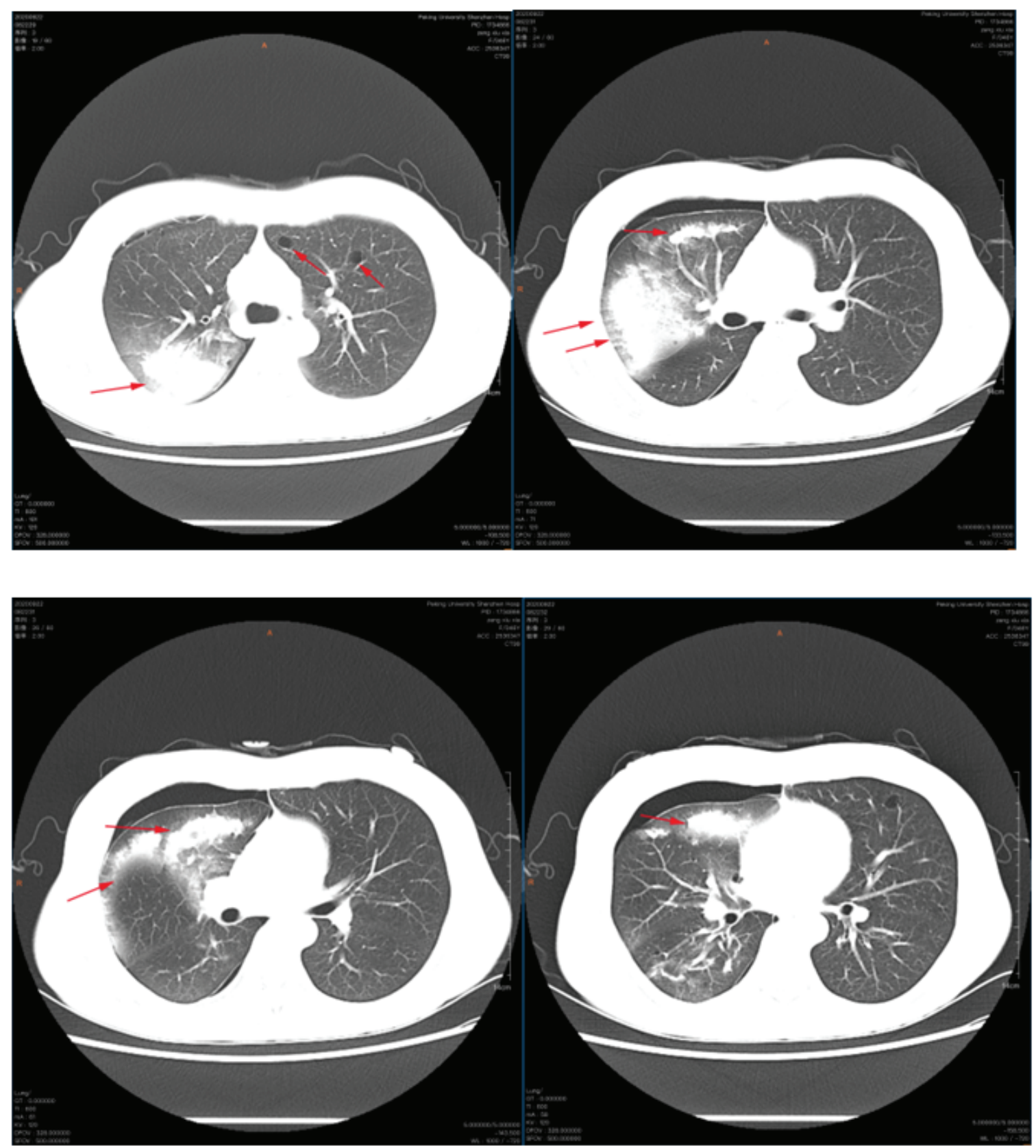

Figure 2: High-Resolution chest CT scan showed that there were diffuse large and patchy hyperdense shadows in the lung with unclear boundary, and there were multiple quasi circular translucent areas in both lungs.

bullae on the surface of the right lung, large lungs at the tip, anterior segment, right middle lung, and basal segment of the right lower lung. The largest blister is located next to the oblique fissure of the right middle lung, with a diameter of $60 \mathrm{~mm}$. A bulla larger than $10 \mathrm{~mm}$ is removed with endogia. The remaining small pulmonary bullae were removed by ligation and electrocautery (Figure 3). We stop bleeding on the wound, flush the chest cavity, and inject $100 \mathrm{ml}$ of $50 \%$ glucose into the chest cavity to promote pleural fixation.

\section{Pathological examination}

The alveoli were expanded, some of the alveoli were broken and fused to show cyst-like changes, the cell morphology was mild, and the lung interstitium was infiltrated with inflammatory cells and histiocytes. Multiple right pulmonary bullae, size $50 \mathrm{~mm} \times 25 \mathrm{~mm}$ $\times 15 \mathrm{~mm}, 30 \mathrm{~mm} \times 20 \mathrm{~mm} \times 10 \mathrm{~mm}, 20 \mathrm{~mm} \times 10 \mathrm{~mm} \times 10 \mathrm{~mm}$ etc. Pathological diagnosis to LAM accompanied by emphysema and pulmonary bullae (Figure 4).

\section{Final Diagnosis}

Pathologists suspected that the lesions are LAM. Peking University-Hong Kong University of Science and Technology Medical Center Bio cell Research Laboratory also considered that the lesions are LAM. 

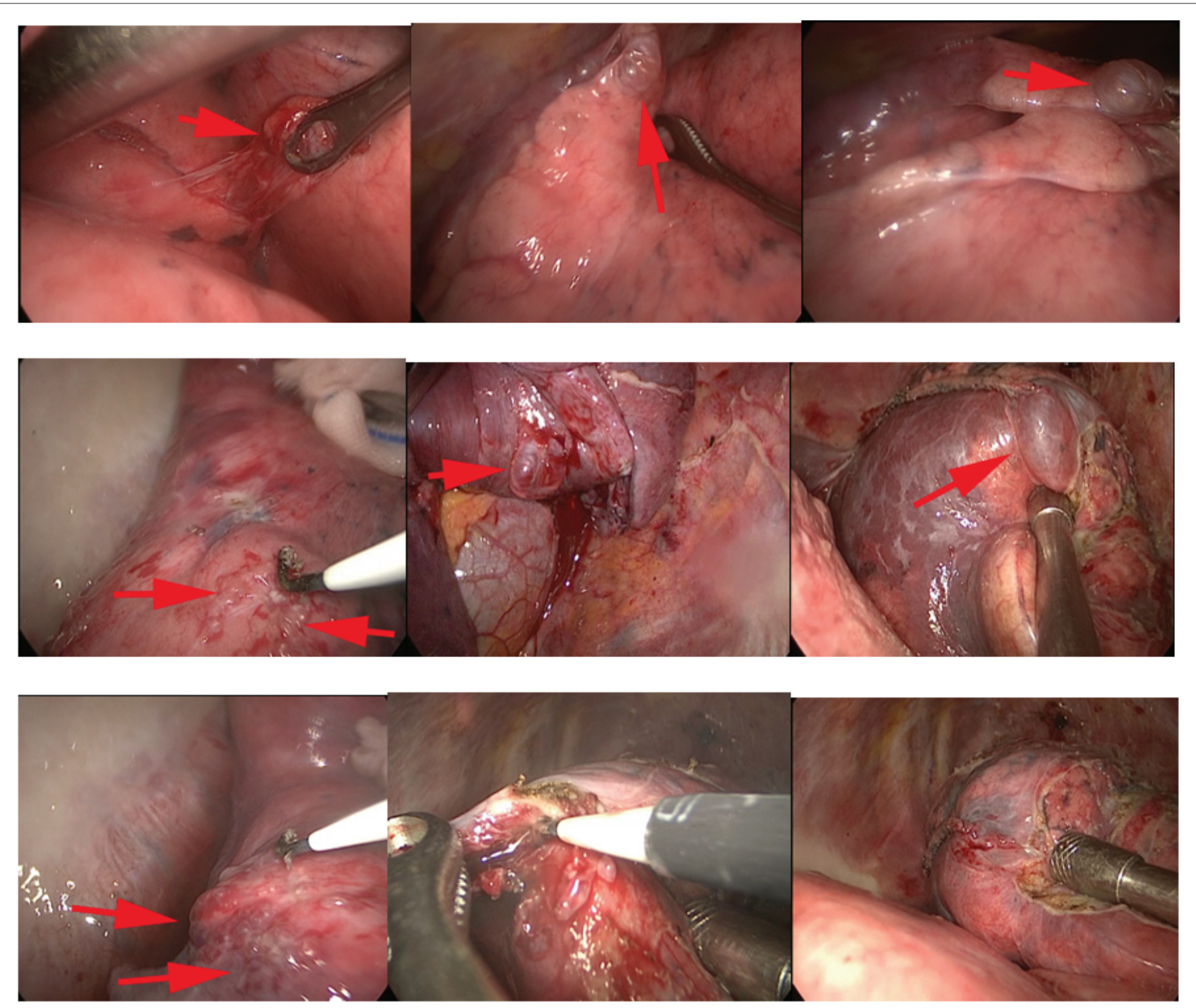

Figure 3: Thoracoscopy showing multiple pulmonary bullae.

\section{Treatment}

We recommend that patients continue to receive treatment after surgery, inform patients of the risk of recurrence of pneumothorax after surgery and to do regular follow-up observations.

\section{Outcome and Follow-up}

The patient refused to stay in the hospital for further observation and treatment, but agreed to reexamination. One month later, the chest $\mathrm{X}$-ray of the patient showed no obvious abnormalities, the right lung was well recruited, chest tightness, chest pain and dyspnea disappeared and no recurrence of pneumothorax and pulmonary bullae.

\section{Discussion}

At present, the cause of LAM is unknown and it often occurs during breastfeeding of women [6]. However, there are also reported male cases of LAM. Patients often see the doctor with repeated pneumothorax and chylothorax.

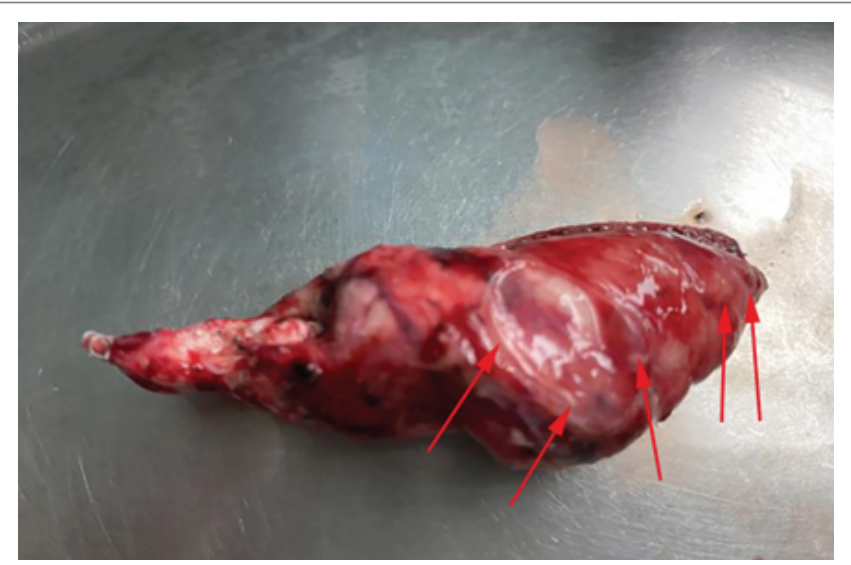

Figure 4: Giant pulmonary bullae after surgical resection, specimen size: $50 \mathrm{~mm} * 25 \mathrm{~mm} * 15 \mathrm{~mm}$. The lung biopsy confirmed the radiographic diagnosis of LAM. 
Table 1: Case reports and experimental projects of the application of thoracoscopic surgery for LAM with multiple pulmonary bullae.

\begin{tabular}{|c|c|c|c|c|c|c|c|}
\hline Study & $\begin{array}{l}\text { Number of } \\
\text { cases }\end{array}$ & $\begin{array}{l}\text { Average } \\
\text { age }\end{array}$ & $\begin{array}{l}\text { Male/ } \\
\text { Female }\end{array}$ & Region & Treatment & $\begin{array}{l}\text { Follow up } \\
\text { time(Month) }\end{array}$ & $\begin{array}{l}\text { Recurrence of } \\
\text { pneumothorax }\end{array}$ \\
\hline $\begin{array}{l}\text { Amir M. Khoja, et al. } 2014 \\
\text { [11] }\end{array}$ & 1 & 41 & $0 / 1$ & India & $\begin{array}{c}\text { VATS+Chemical Pleurodesis or } \\
\text { Pleureectomy }\end{array}$ & 18 & 0 \\
\hline $\begin{array}{l}\text { Masatoshi Kurihara, et al. } \\
2016 \text { [9] }\end{array}$ & 43 & $33(21-53)$ & $0 / 43$ & Japan & VATS+ORC mesh & 36 & 14 \\
\hline $\begin{array}{l}\text { Teruaki Mizobuchi, et al. } \\
2018 \text { [16] }\end{array}$ & 81 & $40(22-68)$ & $46 / 35$ & Japan & VATS+ORC mesh & 60 & 16 \\
\hline John K Reid, et al. 2002 [13] & 1 & 22 & $0 / 1$ & Britain & VATS+progesterone therapy & 84 & 1 \\
\hline Ryo Takahashi 2016 [14] & 112 & $32(17-47)$ & $12 / 100$ & Japan & VATS & 72 & 35 \\
\hline $\begin{array}{l}\text { Kazuhiro Toyoda, et al. } 2006 \\
\text { [10] }\end{array}$ & 1 & 26 & $0 / 1$ & Japan & VATS & 12 & 0 \\
\hline Xin Wang, et al. 2019 [15] & 1 & 64 & $0 / 1$ & China & Thoracoscopic lung resection & 18 & 1 \\
\hline $\begin{array}{l}\text { Tatsusuke Yoshikawa, et al. } \\
1999 \text { [16] }\end{array}$ & 1 & 38 & $0 / 1$ & Japan & VATS+TSLB & 12 & 0 \\
\hline
\end{tabular}

Table 2: Comparison between conservative treatment (Control Group) and thoracoscopic surgery treatment (Experiment Group) in reducing the recurrence rate of LAM pneumothorax.

\begin{tabular}{|c|c|c|c|c|c|c|c|c|}
\hline \multirow{3}{*}{$\begin{array}{c}\text { Study or Sub group } \\
\text { Amir M. Khoja, et al. } 2014 \text { [11] }\end{array}$} & \multicolumn{2}{|c|}{ Experimental } & \multicolumn{2}{|c|}{ Control } & \multirow{3}{*}{$\begin{array}{l}\text { Weight } \\
0.40 \%\end{array}$} & \multirow{3}{*}{$\begin{array}{l}\text { Risk Difference M-H, } \\
\text { Fixed, } 95 \% \mathrm{Cl} \\
-1.00[-1.85,-0.15]\end{array}$} & \multirow{2}{*}{\multicolumn{2}{|c|}{ Risk Difference M-H, Fixed, 95\%Cl }} \\
\hline & \multirow{2}{*}{$\begin{array}{c}\text { Events } \\
0\end{array}$} & \multirow{2}{*}{$\begin{array}{c}\text { Total } \\
1\end{array}$} & \multirow{2}{*}{$\begin{array}{c}\text { Events } \\
1\end{array}$} & \multirow{2}{*}{$\begin{array}{c}\text { Total } \\
1\end{array}$} & & & & \\
\hline & & & & & & & $\leftarrow$ & \\
\hline John K Reid, et al. 2002 [13] & 1 & 1 & 0 & 0 & $0.40 \%$ & $1.00[0.15,1.85]$ & & \\
\hline Kazuhiro Toyoda, et al. 2006 [10] & 0 & 1 & 1 & 1 & $0.40 \%$ & $-1.00[-1.85,-0.15]$ & 4 & \\
\hline Masatoshi Kurihara, et al. 2016 [9] & 14 & 43 & 29 & 43 & $17.80 \%$ & $-0.35[-0.55,-0.15]$ & & \\
\hline Ryo Takahashi 2016 [14] & 35 & 112 & 77 & 112 & $46.50 \%$ & $-0.38[-0.50,-0.25]$ & & \\
\hline Tatsusuke Yoshikawa, et al. 1999 [16] & 0 & 1 & 1 & 1 & $0.40 \%$ & $-1.00[-1.85,-0.15]$ & & \\
\hline Teruaki Mizobuchi, et al. 2018 [12] & 16 & 81 & 65 & 81 & $33.60 \%$ & $-0.60[-0.73,-0.48]$ & & \\
\hline Xin Wang, et al. 2019 [15] & 1 & 1 & 0 & 1 & $0.40 \%$ & $1.00[0.15,1.85]$ & & $\rightarrow$ \\
\hline Total 95\% Cl & & 241 & & 241 & $100.00 \%$ & $-0.44[-0.52,-0.36]$ & & \\
\hline Total events & 64 & & 174 & & & & & \\
\hline $\begin{array}{l}\text { Heterogeneity: } \text { Chi }^{2}=35.93, d f=7 \\
(P<0.00001) ; P=81 \%\end{array}$ & & & & & & & -0.5 & 0. \\
\hline $\begin{array}{l}\text { Test of overall effect: } Z=10.90 \\
(P<0.00001)\end{array}$ & & & & & & & $\begin{array}{c}\text { Favors } \\
\text { (Experimental) }\end{array}$ & Favors (Control) \\
\hline
\end{tabular}

Kebria M, et al. [7] statistied 100 cases of LAM in the United States, and found that in addition to the lungs, the most common parts of LAM can also appear in the mediastinal lymphatic vessels, abdomen, and pelvis. These LAM cases that occur in tissues outside the lungs are rarely reported description. After literature review, we found that very few patients with LAM have extrapulmonary manifestations, which are finally diagnosed under pathological biopsy of extrapulmonary tissues. Matsui K, et al. [8] reported a case of abnormal uterine bleeding that was diagnosed by CT examination evaluation and pathological biopsy. We can see that LAM is not only rare and the clinical manifestations are not specific, which also brings us certain difficulties in diagnosis.
Now, there are many treatment methods for LAM patients, which are mainly divided into two categories:

1. Conservative treatment of drugs. Including rapamycin, doxycycline, etc. Many research projects are being applied and carried out on rapamycin, In the clinical trials of doxycycline in the treatment of LAM, some experiment data showed that its efficacy is obvious, and it can significantly reduce the recurrence rate of bullae and chylothorax, and it provide more options for the treatment of LAM.

2. Thoracoscopic surgical treatment. Matsui K, et al. [9] developed a total pleural cover (TPC) based on VATS, which is a kind of oxidized regenerated cellulose (ORC) mesh that can wrap the whole visceral pleura, this method can strengthen the lung membrane 
and reduce the recurrence of bullae. TPC obviously reduced the incidence of pneumothorax $(0.544 \pm 0.606, \mathrm{P}<0.0001)$. Toyoda $\mathrm{K}$, et al. [10] reported a 26-year-old pregnant woman with complications of lymphangiomyomatosis and idiopathic thrombocytopenic purpura underwent surgical resection of multiple pulmonary bullae under VATS. At that time, the patient developed a pneumothorax at 4 months of pregnancy, and conservative treatment with drugs was recommended. 3 months later, the patient recurred pneumothorax again, we use high-dose intravenous gamma globulin treatment for the patient, but the effect was not obvious. Finally, we decided to use thoracoscopy to resect multiple bullae of both lungs. The patient's chest tightness disappeared after the operation, and the chest X-ray examination was repeated 2 months later, and no obvious pneumothorax recurrence was found. Although thoracoscopic surgery for LAM with pulmonary bullae can effectively reduce the recurrence rate of pneumothorax, not all patients with LAM are suitable for VATS treatment. Duggal D, et al. [11] deems that VATS is only used as a temporary relief operation in India. For patients with recurrent pneumothorax, Damanjit Duggal likes to use bilateral bullous resection with cauterization and mechanical and chemical pleurodesis. Thoracic surgeon in different regions may have various surgical ways for the treatment of LAM with pneumothorax, but their view of common treatment methods is still inclined to use surgical treatment to have more advantages than conservative medical treatment.

We reviewed the literature and summarized the case reports and experimental projects of the application of thoracoscopic surgery for LAM with multiple pulmonary bullae (Table 1).

We want to explore the comparison between conservative treatment (Control Group) and thoracoscopic surgery treatment (Experiment Group) in reducing the recurrence rate of LAM pneumothorax. Therefore, we searched and screened 8 articles on the treatment of LAM with thoracoscopic surgery. We meta-analyzed the pneumothorax recurrence rate of LAM in 8 studies [9,11-16] (Table 2).

We conducted a meta-analysis of 8 case reports and experimental studies [9,11-16] showed that VATS treatment of pneumothorax, the recurrence of pneumothorax was reduced compared with conservative treatment (non-surgical treatment control group) [67/174, 95\% CI:$0.44[-0.52,-0.36], \mathrm{P}<0.00001]$, statistics also have research meaning. Among them, $\mathrm{I}_{2}>50 \%\left(\mathrm{I}_{2}=81 \%\right)$, we conducted statistical bias analysis. Because LAM is a rare disease, relevant literature reports are often reported as individual cases and reported rarely. It leads to $\mathrm{I}_{2}$ increases. In addition, it may also be because the statistical methods of the included literature are different and the difference in the inclusion criteria also causes this bias result.

With the continuous progress of more and more clinical trials and basic research, LAM is no longer an incurable disease. Many regions are constantly exploring the pathogenesis and treatment options of LAM [17]. At present, many thoracoscopic surgical treatments of LAM are mostly based on VATS, with additional TPC or pleurodesis as the main line of treatment.

After surgery, Everolimus (10mg/day) or Sirolimus ( $1 \sim 4 \mathrm{mg} /$ day $)$ [18] will be used. The combination of treatment and drug therapy achieves the best effect for treating LAM, and strives to minimize the recurrence rate of LAM pneumothorax. Drug therapy is an indispensable process after VATS of LAM. The target of rapamycin is mTOR $[19,20]$. Patients with LAM have mutations in the TSC1/TSC2 gene and lose their inhibitory effect on mTOR. Therefore, the signaling pathway activation of mTOR leads to smooth muscle abnormal proliferation. Himes BE and Obraztsova K, et al. [21] reported the results of rapamycin in the treatment of LAM: During a 1 year observation, 8 out of 10 LAM patients had significant improvement in lung function, FEV1 improved by $168 \mathrm{ml}(-40 \sim 470 \mathrm{ml})$, FVC has improved $435 \mathrm{ml}(-120 \sim 1100 \mathrm{ml})$ and reduce residual air volume by $425 \mathrm{ml}$ on average. There is a substance in the urine of LAM patients called matrix metalloproteinase (MMP), and doxycycline has the effect of inhibiting MMP. In the New England Journal, it once reported $[22,23]$ that a case of LAM patients received doxycycline treatment results: the patient's lung function was significantly improved, FEV1 increased from $21 \%$ to $35 \%$ after treatment (proportion to the expected value), and oxygen saturation and activity endurance have been significantly improved.

With the deepening of LAM research, new treatments are constantly being applied to actual clinical practice. In the future, there will be more new drug developments and more perfect surgical procedures for patients with LAM to choose from patients with serious conditions can consider lung transplantation [24,25]. In other treatments, individualized treatments are also required according to clinical conditions.

\section{Conclusion}

Surgical treatment of LAM under thoracoscopy is the most recent direct treatment to relieve pneumothorax. Although the recurrence rate of pneumothorax after thoracoscopic surgery is still high, it has been obviously reduced pneumothorax recurrence rate compared with traditional medical conservative treatment.

\section{Fund Project}

This work was supported by grants from the National Natural Science Foundation of China (81972829), the Science and Technology Innovation Committee of Shenzhen Municipality (Grant No. JCYJ20180228162607111, JCYJ20190809104601662), the Health and Family Planning Commission of Shenzhen Municipality Research Project (Grant No. SZBC2018018), China Scholarship Council (CSC, 201908470124).

\section{Statement of Ethics}

The authors have no ethical conflicts to disclose.

\section{Disclosure Statement}

The authors have no conflicts of interest to declare.

\section{References}

1. Gupta N, Henske EP (2018) Pulmonary Manifestations in Tuberous Sclerosis Complex. Am J Med Genet C Semin Med Genet 178: 326-337.

2. Correia-Neves M, Fröberg G, Korshun L, Viegas S, Vaz P, et al. (2019) Biomarkers for Tuberculosis: The Case for Lipoarabinomannan. ERJ Open Res 5.

3. Grzegorek I, Drozdz K, Podhorska-Okolow M, Szuba A, Dziegiel P (2013) LAM Cells Biology and Lymphangioleiomyomatosis. Folia Histochem Cytobiol 51: 1-10.

4. Lam SC, Yuen HKL (2019) Medical and Sclerosing Agents in the Treatment of Orbital Lymphatic Malformations: What's New? Curr Opin Ophthalmol 30: 380-385.

5. Taillé C, Borie R, Crestani B (2011) Current Management of Lymphangioleiomyomatosis. Curr Opin Pulm Med 17: 374-378.

6. Volløyhaug I, Taithongchai A, Gruting IA, Sultan A, Thakar R (2019) Levator Ani Muscle Morphology and Function in Women with Obstetric anal Sphincter Injury. Ultrasound Obstet Gynecol 53: 410416. 
7. Kebria M, Black D, Borelli C, Modica I, Hensley M, et al. (2007) Primary Retroperitoneal Lymphangioleiomyomatosis in a Postmenopausal Woman: A Case Report and Review of the Literature. Int J Gynecol Cancer 17: 528-532.

8. Matsui K, Tatsuguchi A, Valencia J, Yu ZX, Bechtle J, et al. (2000) Extrapulmonary Lymphangioleiomyomatosis (LAM): Clinicopathologic Features in 22 Cases. Hum Pathol 31: 1242-1248.

9. Kurihara M, Mizobuchi T, Kataoka H, Sato T, Kumasaka T, et al. (2016) A Total Pleural Covering for Lymphangioleiomyomatosis Prevents Pneumothorax Recurrence. PLoS One 11: e0163637.

10. Toyoda K, Matsumoto K, Inoue H, Komori M, Fujita M, et al. (2006) A Pregnant Woman with Complications of Lymphangioleiomyomatosis and Idiopathic Thrombocytopenic Purpura. Intern Med 45: 10971100.

11. Khoja AM, Duggal D, Keni A, Patel CS, Chavan R (2014) Palliative Management of Lymphangioleiomyomatosis: Using Video-assisted Thoracoscopic Surgery. J Bronchology Interv Pulmonol 21: 54-57.

12. Mizobuchi T, Kurihara M, Ebana $\mathrm{H}$, Yamanaka S, Kataoka $\mathrm{H}$, et al. (2018) A Total Pleural Covering of Absorbable Cellulose Mesh Prevents Pneumothorax Recurrence in Patients with Birt-HoggDubé Syndrome. Orphanet J Rare Dis 13: 78.

13. Reid JK, Rees H, Cockcroft D (2002) Long Term Survival in a Patient with Pulmonary Lymphangioleiomyomatosis. Can Respir J 9: 342346.

14. Takahashi R (2016) Evaluation of Spontaneous Pneumothorax Surgeries: A 16-Year Experience in Japan. Surg Res Pract.

15. Wang X, Li P, Zhou P, Fu Y, Lai $Y$, et al. (2019) Intrapulmonary Metastasis from Primary Pulmonary Meningioma Presenting as Multiple Cystic Lesions: A Case Report. BMC Pulm Med 19: 8.

16. Yoshikawa T, Wajima Z, Ogura A, Imanaga K, Inoue T (2000) Thoracoscopic Lung Biopsy in a Patient with Pulmonary Lymphangiomyomatosis. Can J Anaesth 47: 62-64.
17. Shaaban OM, Hassen SG, Nour SA, Kames MA, Yones EM (2013) Emergency Contraceptive Pills as a Backup for Lactational Amenorrhea Method (LAM) of Contraception: A Randomized Controlled Trial. Contraception 87: 363-369.

18. McCormack FX, Inoue $Y$, Moss J, Singer LG, Strange C, et al. (2011) Efficacy and Safety of Sirolimus in Lymphangioleiomyomatosis. N Engl J Med 364: 1595-1606.

19. Bissler JJ, Kingswood JC, Radzikowska E, Zonnenberg BA, Frost M, et al. (2016) Everolimus for Renal Angiomyolipoma in Patients with Tuberous Sclerosis Complex or Sporadic Lymphangioleiomyomatosis: Extension of a Randomized Controlled Trial. Nephrol Dial Transplant 31: 111-119.

20. Mannick JB, Del Giudice G, Lattanzi M, Valiante NM, Praestgaard J, et al. (2014) mTOR Inhibition Improves Immune Function in the Elderly. Sci Transl Med 6: 268ra179.

21. Himes BE, Obraztsova K, Lian L, Shumyatcher M, Rue R, et al. (2018) Rapamycin-Independent IGF2 Expression in Tsc2-null Mouse Embryo Fibroblasts and Human Lymphangioleiomyomatosis Cells. PLoS One 13: e0197105.

22. Chang WYC, Clements D, Johnson SR (2010) Effect of Doxycycline on Proliferation, MMP Production, and Adhesion in LAM-Related Cells. Am J Physiol Lung Cell Mol Physiol 299: L393-L400.

23. Khawar MU, Yazdani D, Zhu Z, Jandarov R, Dilling DF, et al. (2019) Clinical Outcomes and Survival Following Lung Transplantation in Patients with Lymphangioleiomyomatosis. J Heart Lung Transplant 38: 949-955.

24. Isik A, Ramanathan R (2020) Approaches to the Treatment of Pilonidal Sinus Disease, Clinical Practice in 2019. Int Wound J 17: 508-509.

25. Isik A, Isik N, Kurnaz E (2020) Complete Breast Autoamputation: Clinical Image. Breast J 26: 2265-2266. 